\title{
The invasive Opuntia ficus-indica homogenizes native plant species compositions in the highlands of Eritrea
}

\author{
Yohannes B. Tesfay (iD · Juergen Kreyling
}

Received: 30 March 2020/Accepted: 20 September 2020/Published online: 6 October 2020

(C) The Author(s) 2020

\begin{abstract}
Invasion by exotic species is recognized as one of the major threats to biodiversity. The effects of invasion by Opuntia ficus-indica (Cactaceae) on the species diversity, richness and composition of invaded communities were studied at three sites in the highlands of Eritrea, East Africa. This paper investigates whether the presence of $O$. ficus-indica causes a negative effect on the native biodiversity in a region rarely studied so far. The vegetation in invaded and uninvaded plots with similar habitat conditions was sampled and differences in the species composition, diversity and richness were compared between the plots. The overall plant species composition differed significantly with invasion by $O$. ficus-indica. The invasion by $O$. ficus-indica also led to a significant homogenization of community compositions. The species richness and Shannon diversity index did not differ significantly between the invaded and uninvaded plots. Nevertheless, we still detected species
\end{abstract}

Electronic supplementary material The online version of this article (https://doi.org/10.1007/s10530-020-02373-8) contains supplementary material, which is available to authorized users.

\section{Y. B. Tesfay $(\bowtie) \cdot$ J. Kreyling}

Experimental Plant Ecology, Institute of Botany and

Landscape Ecology, University of Greifswald,

Soldmannstrasse 15, 17489 Greifswald, Germany

e-mail: yohannes.tesfay@stud.uni-greifswald.de

J. Kreyling

e-mail: juergen.kreyling@uni-greifswald.de with significantly lower occurrence in the invaded plots (Psiadia punctulata), but also species which preferred invaded plots (Plectranthus hadiensis). We conclude that $O$. ficus-indica exerts a negligible effect on the species diversity and richness but that it affects species composition and that there are species which suffer due to its presence. Due to the continuous pressure of the invasion by $O$. ficus-indica on the species composition and dry climates, further homogenization in the native species diversity is to be expected in the future for the highlands of Eritrea.

Keywords Eritrea Opuntia ficus-indica Plant invasions - Species composition - Species diversity · East-African highlands

\section{Introduction}

Invasion by introduced exotic species is recognized as one of the major environmental problems and threats to biodiversity (Di Castri et al. 1989; Di Castri and Hansen 1990; Williamson 1996). Many of the deliberate introductions relate to the human interest in nurturing species for agricultural, forestry or ornamental uses (Staples 2001). Invasion by exotic plant species can significantly alter the native plant community composition and ecosystem processes (Vilà et al. 2011), although the types and magnitudes of 
impacts of individual invasive species can vary with the type of ecosystem or invasive species (Fridley et al. 2007; Stohlgren and Rejmànek 2014). Even though some studies argue that plant invasions rarely cause biodiversity loss (Sax et al. 2002; Gurevitch and Padilla 2004; Maskell et al. 2006; Stohlgren et al. 2008), others have shown significant declines in biodiversity due to introduced invasive plants (Wilcove et al. 1998; Pimentel et al. 2001; Pauchard and Shea 2006). Various invasive plants are also known to change species composition or diversity (Vilà et al. 2006; Gaertner et al. 2009; Hejda et al. 2009; Powell et al. 2011), decrease ecosystem productivity and alter the rate of nutrient cycling (Liao et al. 2008; Ehrenfeld 2003), and hence impact ecosystem services and human well-being (Pejchar and Mooney 2009). Moreover, invasive species have been considered important agents in homogenizing plant communities at spatially different levels (Dar and Reshi 2015; Lososová et al. 2016; Price et al. 2018). Biotic homogenization is the process of increasing similarity among previously distinct communities within a specific region (Olden and Rooney 2006; Smart et al. 2006) and plant invasions may cause homogenization of the natural habitats by adapting to the new environmental conditions and dominating the native vegetation (Van Kleunen et al. 2010; Sol et al. 2012; Morri et al. 2019).

Invasiveness is influenced by species traits and describes the extent to which an alien species can overcome biotic and abiotic barriers to establishment and spread in a new environment (Richardson and Pyšek 2006; Wilson et al. 2007). Invasive plants are successful due to several reasons. They can produce many viable seeds, be unpalatable to herbivores, easily establish in different environments, tolerate highly stressful conditions and/or have an ability to readily regenerate from seeds, stems or roots. These features enable them to survive, spread and ultimately impact the native ecosystem (Obiri 2011). Opuntia ficusindica (prickly pear), native to Mexico, is an exceptionally successful drought-tolerant invasive cactus that grows in arid and semi-arid areas. Opuntia ficusindica is considered as an ecosystem engineer as it modifies the habitats of the indigenous plant species and dependent animals (Jones et al. 1994). This species impedes the movement of livestock and humans as it forms impenetrable thickets. It displaces native plants and reduces the carrying capacity of pasture and particularly threatens large-scale cattle ranching (Obiri 2011). Opuntia ficus-indica occurs in countries where it has been cultivated and is invasive in Australia, Eritrea, Ethiopia, South Africa, Hawaii, USA and also to some extent in Somalia and Yemen (Brutsch and Zimmermann 1995), as well as in the tropical forests and rangelands of Kenya and Tanzania (Obiri 2011, Oduor et al. 2018). Additionally, Novoa et al. (2015) report that O. ficus-indica is the most widespread invasive cactus distributed outside the native range in 22 different countries.

In Eritrea, O. ficus-indica is highly invasive and abundant with an estimated cover of about 10,000 ha in the highlands, especially on the eastern escarpments (Bein et al. 1996). There is no clear evidence as to when $O$. ficus-indica was introduced into Eritrea, but it is assumed to have been planted in the southern parts of the highlands as early as 1839 and was then brought to the central highlands (NEMP-E 1995). The fruit of O. ficus-indica is popular as food for humans as well as animals. Outweighing its benefits, O. ficus-indica is invading the highlands, potentially causing changes in the ecological functioning of the native Afromontane forests, which, according to White (1983), is one of the major regional centres of endemism. The Invasive Woody Plant Database comprises over 5000 publications on species invasiveness, whereby only $6 \%$ refer to tropical Africa (Obiri 2011). This implies that the pressure on the native diversity in the region has rarely been studied and we are unaware of any comparable studies in Eritrea.

This paper analyses the ecological impacts of $O$. ficus-indica on the native plant diversity in Eritrea. We hypothesized that the spread of $O$. ficus-indica affects the composition, diversity and richness of the native plant species. Additionally, we measured environmental factors that potentially influence the invasion of the plant. We hypothesized that O. ficus-indica thrives in higher elevations, steep slopes and shallow soil depths. This was mainly because $O$. ficus-indica has been planted in Eritrea for soil conservation and to prevent erosion at steep slopes and higher altitudes (Bein et al. 1996). All these assumptions were tested using original field data, based on the comparisons of vegetation with and without $O$. ficus-indica. 


\section{Materials and methods}

\section{Study species}

Opuntia ficus-indica is an evergreen perennial plant that can grow up to $5 \mathrm{~m}$ in height. The species has succulent stems that are formed as a sequence of flattened segments, the cladodes, which generally have an elliptical base that supports the greatly enlarged, flattened upper portion. Opuntia ficus-indica has spines, morphologically corresponding to leaves. Its flowers $(5-10 \mathrm{~cm}$ in diameter) are sessile and solitary, and the fruits are berries that are $4-8 \mathrm{~cm}$ in diameter (Gimeno and Vilà 2002) with an average of 273 seeds per fruit (Barbera et al. 1991). Nieddu and Chessa (1997) found the germination of the O. ficusindica seeds reaching up to $90 \%$ in growth chambers with a day/night temperature of $30 / 20^{\circ} \mathrm{C}$, but only reaching 55\% when seeds were kept at room temperature and $43 \%$ when seeds were placed outdoors. The seeds are usually dispersed after consumption by humans, birds and other animals (endozoochory). Furthermore, vegetative propagation occurs through cladodes readily taking root upon falling to the ground and conspicuous patch formation is an important factor in the persistence of local populations of the plant, although seedling recruitment is essential for expanding the geographic range and establishment in new areas (Gimeno and Vilà 2002).

\section{Study site}

The study was conducted in the central highlands of Eritrea, where $O$. ficus-indica grows vigorously and is abundant. The central highlands lie at an altitude over $1500 \mathrm{~m}$ with a mean annual rainfall of $500 \mathrm{~mm}$. It is an area with a warm to cool semi-arid climate and potential evapotranspiration ranging between 1300 and $1800 \mathrm{~mm}$. In this area, the rainy season normally lasts about three months, beginning in June and ending in August. Besides heavy rain, occasional showers come in March and April (Ogbazghi and Stillhardt 2011). The vegetation map of Africa by White (1983) lists 20 major regional centres of endemism, of which four (the Sudanian, Somali-Massai, Afromontane, and Sahel regions) are well represented in Eritrea. The natural vegetation of the study site is the dry part of the Afromontane regional centre of endemism. The flora as a whole is estimated to contain over 4000 taxa, of which $75 \%$ are likely to be endemic to the Afromontane regional centre (Ogbazghi and Stillhardt 2011). Despite this regional taxonomic richness, plot-level species richness is remarkably low, especially compared to the richness of higher taxonomic units (Hamilton 1976; Bekele 1994; Tura et al. 2017).

\section{Sampling design}

The ecological data were collected from June to August 2018. The fieldwork was conducted during and shortly after the rainy season for an effective sampling of the existing plant species because most of them sprout, leaf out and/or produce fruits during this time. Representative original habitats were selected at three different sites (Fig. 1) to identify and assess the ecological impacts of $O$. ficus-indica. The aim was selecting a wide range of habitats where $O$. ficusindica has established sustained populations in the central highlands of Eritrea: (a) a relatively humid site in which O. ficus-indica was historically favoured by people for collection of fruits and free grazing takes place (site 1), (b) a rocky site and relatively dryer than the other two sites (site 2), and (c) a site protected from human use (site 3). This selection of contrasting sites provided a general picture of invasive success and its impact in the Eritrean highlands. At each site, we compared $O$. ficus-indica invaded areas with surrounding uninvaded areas, in which the uninvaded control plots were located as close to the invaded plots as possible to have similar site conditions $(5-10 \mathrm{~m}$ distance). A total of 36 pairs of plots (12 pairs for each site and each plot measuring $10 \times 10 \mathrm{~m}$ ) were sampled to assess the potential effects of $O$. ficusindica (Table 1). The pairs of plots represented the $O$. ficus-indica invaded group and the non-invaded or control group. In each of the plots, the floristic composition of the understory vegetation, the shrub layer and the tree layer were recorded and their covers estimated. The sampling approach was to examine species composition and to compare species richness and diversity estimates between $O$. ficus-indica invaded and uninvaded plots. Plant species were identified following Hedberg and Edwards (1989); Edwards et al. (1995); Edwards et al. (1997); Edwards et al. (2000); Hedberg et al. (2003); Hedberg et al. (2006); Mesfin (2004) and Bein et al. (1996). For 


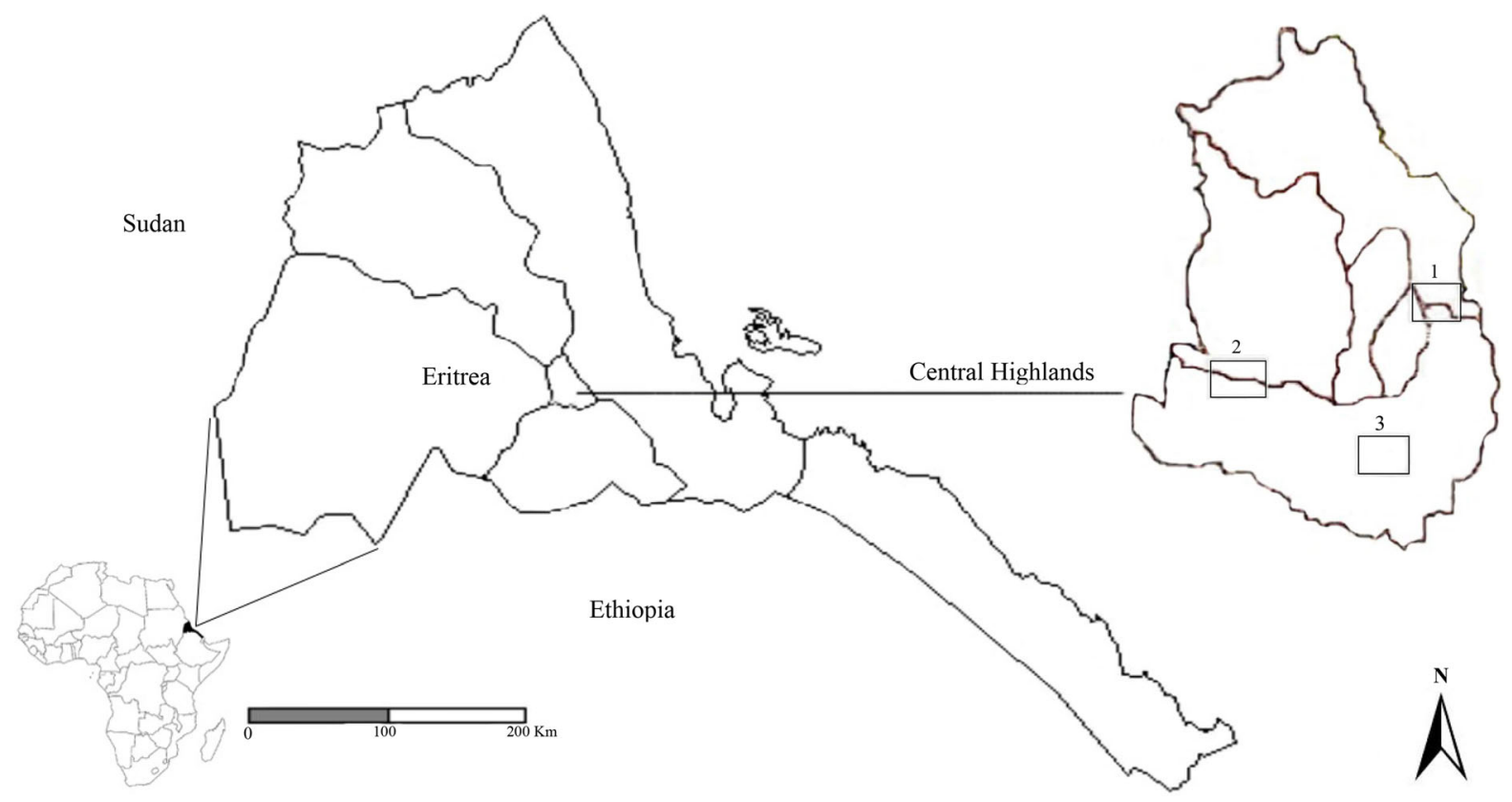

Fig. 1 A map of the study area and the three study sites in the highlands of Eritrea

Table 1 Basic geographical characteristics (average representation per site) of the three sites where the data were collected (Fig. 1). See Online Resource 1 for detailed information of each plot

\begin{tabular}{|c|c|c|c|c|c|c|}
\hline Site & Position & Altitude (m a.s.l) & Slope $\left(^{\circ}\right)$ & Soil depth $(\mathrm{cm})$ & Soil $\mathrm{pH}$ & No of plots \\
\hline 1 & $15.345 \mathrm{~N} 38.962 \mathrm{E}$ & $2395 \pm 8$ & $15 \pm 2.8$ & $12 \pm 2.5$ & $6.3 \pm 0.4$ & 24 \\
\hline 2 & $15.248 \mathrm{~N} 38.762 \mathrm{E}$ & $2198 \pm 6.6$ & $8 \pm 1.2$ & $8 \pm 1.2$ & $6.4 \pm 0.5$ & 24 \\
\hline 3 & $15.231 \mathrm{~N} 38.899 \mathrm{E}$ & $2245 \pm 8$ & $9 \pm 2.9$ & $12 \pm 1.9$ & $6.4 \pm 0.4$ & 24 \\
\hline
\end{tabular}

accurate identification of some species, specimens were taken to the Herbarium of the Eritrea Institute of Technology. Additionally, environmental factors such as elevation in meters above sea level, soil $\mathrm{pH}$ measured in water, slope in degrees and soil depth in centimetres were measured. An average value of samples from three sides of each plot was taken to equally represent the environmental parameters.

\section{Statistical analyses}

We calculated differences in the composition of vascular plant species between the invaded and uninvaded plots of the three sites using an analysis of similarity (ANOSIM) with the function anosim in the vegan package (version 2.5-6; Oksanen et al. 2019). To assess the degree of similarity in community composition between plots, we computed the Bray-
Curtis dissimilarity index. This was performed based on the native species abundance. The values of BrayCurtis dissimilarity index fall between 0 , where the two communities are identical and 1 , where the two communities are completely dissimilar and share no common species. Based on Bray-Curtis dissimilarity, we further tested for homogenization of the native plant communities by comparing the mean dissimilarity of invaded and non-invaded plots. Because of lack of independence in the data due to each plot being used for n-1 pairwise dissimilarity calculations, we tested for significance of differences in mean dissimilarity between the two groups by a permutation procedure which compared the observed difference in means to 1000 random draws (Jurasinski and Kreyling 2007). Then, non-metric multidimensional scaling (NMDS) (Kruskal 1964) was used to collapse the information of species compositions to two 
dimensions for better visualization and interpretation. Additionally, the significant environmental vectors (elevation, slope and soil depth) were fitted into the ordination space using the function envfit in the vegan package. Furthermore, species that were significantly affected in their occurrence by the presence of $O$. ficus-indica were identified with an indicator species analysis (Dufrêne and Legendre 1997) using the indval function in labdsv package (version 2.0-1; Roberts 2019). The presence or absence of $O$. ficus-indica was used to differentiate the invaded and control plots. Thus, we excluded $O$. ficus-indica while calculating community composition or species richness. We fitted a linear mixed-effects model and used ANOVA (lmerTest package, version 3.1-0; Kuznetsova et al. 2017 ) to assess the effects of $O$. ficus-indica on indices of species diversity in which the indices of diversity were treated as dependent variables while invasion status of a plot was treated as a fixed-effect independent variable. Plot pair was nested within the study site and treated as a random-effect independent variable. Native species richness and Shannon diversity index were calculated and compared between control and invaded plots in the same way. All statistical analyses were performed in $\mathrm{R}$ (version 3.6.0; $\mathrm{R}$ Core Team 2019).

\section{Results}

A total of 45 plant species were identified from 25 families on the 36 pairs of plots (see Online Resource 2). The dominant families were Asteraceae, Lamiaceae, Fabaceae and Solanaceae. In the invaded plots, O. ficus-indica reached an average cover of $49 \% \pm$ $18 \%$ (SD). The number of juvenile $O$. ficus-indica increased with the number of adult $O$. ficus-indica $\left(p=0.026 ; \mathrm{r}^{2}=0.14\right)$ and a total cover of $O$. ficusindica $\left(p=0.001 ; \mathrm{r}^{2}=0.26\right)$, indicating its potential to form dense and lasting thickets once established.

The overall plant species composition between the pairs of invaded and uninvaded plots of the sites differed significantly (ANOSIM: $\mathrm{R}=0.24$; $p<0.001$, Fig. 2). The invasion by $O$. ficus-indica led to a significant homogenization of community compositions (Fig. 3, permutation test: $\mathrm{F}=19.6$, $p<0.001)$. The environmental parameters with significant $(p<0.05)$ link to the plant species composition, in addition to the described effect of invasion by
O. ficus-indica, were elevation, slope and soil depth of the plots (Fig. 3). This result corresponded well with univariate regressions showing higher cover by $O$. ficus-indica with increasing altitude $\left(p=0.002 ; \mathrm{R}^{2}=\right.$ $0.23)$, increasing slope $\left(p=0.050 ; \mathrm{R}^{2}=0.11\right)$ and increasing soil depth $\left(p=0.005 ; \mathrm{R}^{2}=0.21\right)$. The indicator species analysis (see Online Resource 2) revealed that Plectranthus hadiensis $(p=0.007)$ occurred together with $O$. ficus-indica more often, while Psiadia punctulata occurred more often in the absence of $O$. ficus-indica $(p=0.041)$.

The indicator species analysis showed that Bidens pilosa $(p=0.10)$ and Tagetes minuta $(p=0.22)$, which are themselves invasive species, had no significant link to the plots invaded by $O$. ficus-indica. We also checked their role in homogenization of communities by comparing plots where they were present to plots where they were absent. The results based on the subset of sites where the species occurred, Tagetus minuta $(p=0.501)$ and Bidens pilosa $(p=0.165)$ did not exert a significant effect on homogenization.

The species richness $(p=0.311)$ and Shannon diversity index ( $p=0.098)$ did not differ significantly between the invaded and uninvaded plots. Furthermore, species richness and Shannon diversity were not significantly related to the cover of $O$. ficus-indica ( $p=0.226$ and $p=0.191$, respectively).

\section{Discussion}

Our results showed that species composition of the plant communities was significantly homogenized by the presence of $O$. ficus-indica while species richness and Shannon diversity were not significantly affected by the presence of $O$. ficus-indica. This suggests that the spread and abundance of $O$. ficus-indica reduce landscape-level heterogeneity or spatial diversity (Jurasinski and Kreyling 2007) of the native plant communities. This finding corresponds well with other studies which have shown homogenization of native plant communities due to invasive species (McKinney 2005; Olden and Rooney 2006; Pino et al. 2009; Qian and Ricklefs 2006). Chen et al. (2013), for example, found that Solidago canadensis invasions have resulted in community homogenization across diverse habitats and landscapes which were formerly dominated by different species. They concluded that the community patterns of sites invaded by $S$. canadensis 


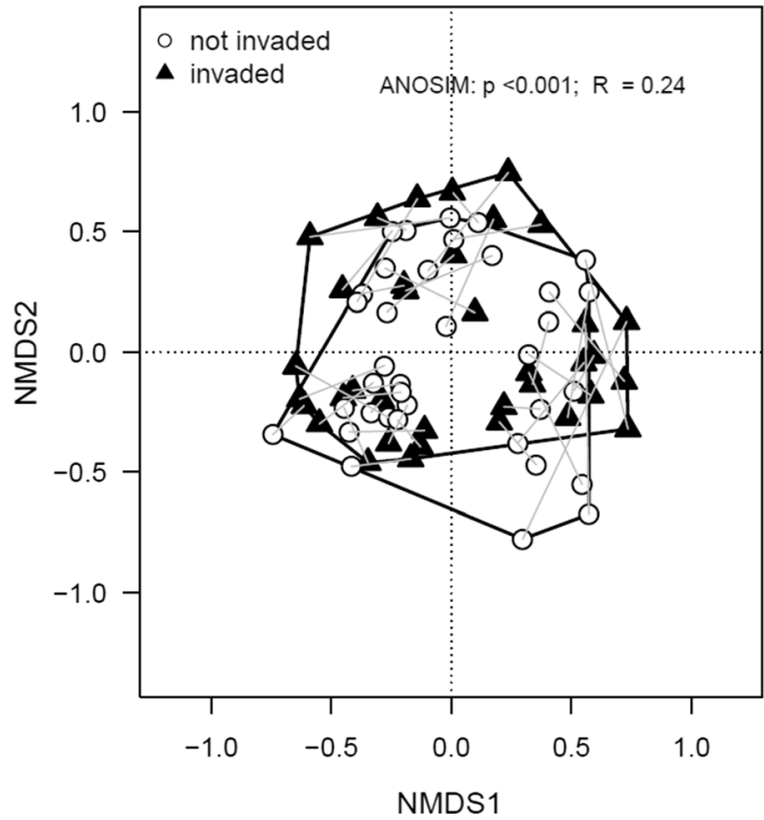

Fig. 2 The difference in species compositions between invaded and non-invaded plots graphically visualized by non-metric multidimensional scaling (NMDS). Statistics stem from an analysis of similarity (ANOSIM) based on Bray-Curtis

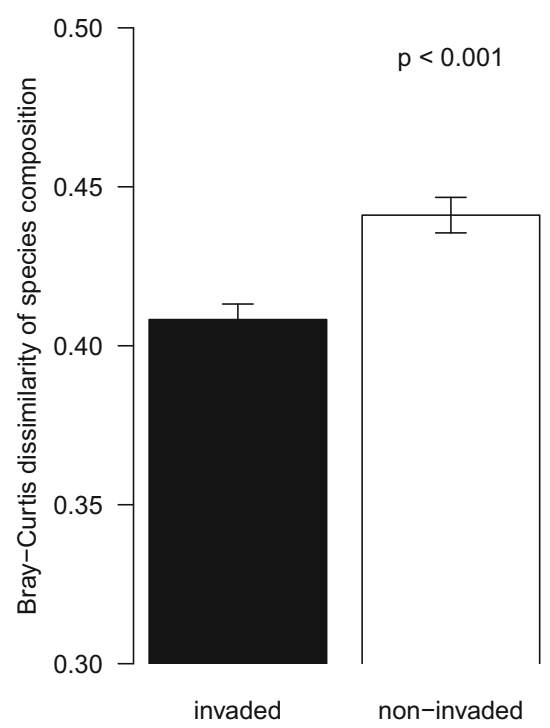

Fig. 3 Invasion by $O$. ficus-indica led to the homogenization of native plant community compositions as indicated by a decrease in mean Bray-Curtis dissimilarity. Displayed are the mean \pm 1 SE of all pairwise Bray-Curtis dissimilarities per group. Significance of the differences between the invaded and adjacent uninvaded plots was tested using a permutation test with 1000 permutations

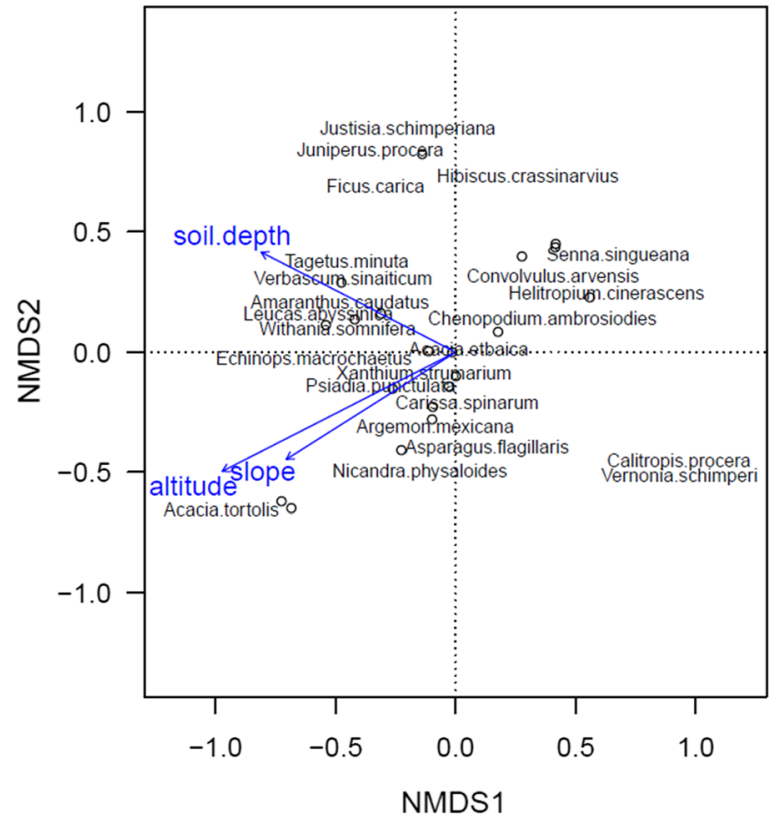

dissimilarity with final two-dimensional stress of 0.23 . Species occurrence in the ordination and significant environmental parameters depicted in blue are shown for the same ordination in the second panel. See Online Resource 2 for the full species list

were highly similar to each other but dissimilar to those in the control sites, a scenario that corresponds to the homogenizing nature of invasive plants.

The ability to form homogenous stands, which is typical for $O$. ficus-indica, appears to drive the interference with the native species (Zimmermann et al. 2009). It has previously been reported that invasions can have a limited effect on species richness of communities (Hejda and Pyšek 2006). However, changes in species composition can occur and native, fast-growing species can increase in abundance in the invaded communities. Accordingly, we found Plectranthus hadiensis, a semi-succulent fast-growing herbaceous plant to occur more frequently with $O$. ficus-indica. On the other hand, Psiadia punctulata, a drought-resistant East African shrub was found to avoid the presence of the invasive plant. It is reported that $P$. punctulata is usually avoided by some herbivore animals even during severe drought conditions. An exudate, rich in pharmacologically active secondary metabolites, is potentially responsible for its unpalatable nature and drought resistance (Midiwo et al. 2003; Juma et al. 2001; Juma et al. 2006). We thus hypothesize that one important impact of the presence of $O$. ficus-indica on native diversity occurs 
through affecting grazing and browsing patterns by herbivores. Opuntia ficus-indica likely shelters species sensitive to herbivory and competes with browsing-tolerant species for space, presumably explaining that its presence showed no significant impact on native species diversity and richness. These results imply that the impact of the invasive $O$. ficus-indica on the diversity and richness of native vegetation may be lower than previously thought. A similar situation was reported from Kenya (Oduor et al. 2018) where a similar study was performed by surveying the native vegetation in Nairobi National Park between O. ficusindica invaded and uninvaded sites. They found that communities invaded by $O$. ficus-indica had significantly higher native species richness and diversity because $O$. ficus-indica sheltered the native species against grazing.

A potential drawback of observational studies comparing invaded and uninvaded habitats is that they may be biased by the fact that species diversity in itself can affect the likelihood of invasion, which makes it difficult to separate cause and effect (Hejda and Pyšek 2006; Levine and D'Antonio 1999; Hulme and Bremner 2006). However, since our results showed no difference in species diversity between invaded and uninvaded communities, the prediction that species-poor stands could have been more easily invaded is irrelevant to our study (Hejda and Pyšek 2006). Quantitatively measuring the impacts of invasive species on native communities in the field is difficult. This is because invasion is a long-term process rarely observed from the time of the introduction and establishment of the invasive species (Müllerová et al. 2005). We used the invaded and uninvaded plots to overcome this difficulty. The uninvaded plots represented the native vegetation before the invasion occurred (Pyšek and Pyšek 1995) which justifies the 'space for time' substitution approach that is often used in studies on vegetation succession (Alvarez and Cushman 2002; Badano and Pugnaire 2004; Ruprecht 2005). The measurements of the species diversity between the invaded and uninvaded plots were then used in quantitively assessing the species richness, diversity and composition of the vegetation.

In its regions of origin, $O$. ficus-indica is found at elevations of over $4700 \mathrm{~m}$ (Nobel 1994) or in the introduced areas such as South Africa and Australia in highlands above $2000 \mathrm{~m}$ (Johnson 1982;
Zimmermann and Moran 1991; van Sittert 2002). It is thus well-fitted to grow in high altitudes, and in our study area at the Eritrean highlands, it grows vigorously and is abundant at elevations around $2000 \mathrm{~m}$. It is a common conception that $O$. ficus-indica is planted for soil conservation and prevents erosion at steep slopes and higher altitudes (Bein et al. 1996), and we thus expected to find it primarily in those habitats. With respect to the effect of the environmental parameters on invasibility, higher cover and invasion success occurred in steeper and higher sites than in flatter sites or at lower elevations. Erre et al. (2009) studied the distribution of $O$. ficus-indica in the Mediterranean Basin and on the contrary found that the invasive plant was not common at higher altitudes due to the low temperatures in the region. The cover of O. ficus-indica also tended to increase with increasing soil depth. This could be attributed to the government's efforts to prevent soil erosion by terracing the landscape in higher altitudes with steep slopes which eventually conserved the soil and resulted in higher soil depths.

The successful establishment of $O$. ficus-indica depends on its unique biological traits and the environmental characteristics of the ecosystems it invades. It is suggested that the fluctuation in resource availability makes plant communities susceptible to invasion (Davis et al. 2000). Water availability in dry climates displays an example for this theory, as temporal fluctuations cause intermittent lack of resource availability, followed by water availability upon rainfall. This pulsed regime of water availability can make communities vulnerable to drought-tolerant invasive specialists such as $O$. ficus-indica. Its invasion success may consequently be amplified by climate change, which leads to warmer and drier conditions in the study area (Funk et al. 2015; Serdeczny et al. 2017) and can be expected to further increase the competitive ability and thereby the invasiveness of $O$. ficus-indica as it originates from even warmer and drier conditions (Novoa et al. 2015). To better project the future invasive potential of $O$. ficus-indica, controlled competition experiments with $O$. ficus-indica and native plants are needed.

Our data show that invasion by $O$. ficus-indica leads to plant community homogenization in the Eritrean highlands. While species richness and diversity appear unaffected by this invasion, homogenization is another negative consequence. Successful recruitment and 
densification of established $O$. ficus-indica stand suggest an intensification of this problem in future, likely exacerbated by climate change and further enhanced by the lack of awareness of the local communities on the impacts of its invasion (Ogbazghi and Stillhardt 2011). The nurturing of the plant for different local uses (e.g. hedging, fodder, edible fruits) utilizing its drought-tolerant nature increases the potential for further spreading of this invasive species (Bein et al. 1996) and the interference with the spatial diversity and ecosystem processes of the native vegetation. It will likely become a long-term dominant species with an increasing impact on the native vegetation. The real challenge now lies in raising the local awareness of the issue and preventing further spread of the species to other natural ecosystems.

Acknowledgements We thank Merhawi F. Habte and Kibrom G. Lekal for their assistance in the fieldwork. Yohannes B. Tesfay was supported by the DFG research training group RESPONSE (RTG 2010) and a scholarship from the German Academic Exchange Service (DAAD).

Funding Open Access funding enabled and organized by Projekt DEAL.

Open Access This article is licensed under a Creative Commons Attribution 4.0 International License, which permits use, sharing, adaptation, distribution and reproduction in any medium or format, as long as you give appropriate credit to the original author(s) and the source, provide a link to the Creative Commons licence, and indicate if changes were made. The images or other third party material in this article are included in the article's Creative Commons licence, unless indicated otherwise in a credit line to the material. If material is not included in the article's Creative Commons licence and your intended use is not permitted by statutory regulation or exceeds the permitted use, you will need to obtain permission directly from the copyright holder. To view a copy of this licence, visit http://creativecommons.org/licenses/by/4.0/.

\section{References}

Alvarez ME, Cushman JH (2002) Community-level consequences of a plant invasion: effects on three habitats in coastal California. Ecol Appl 12:1434-1444. https://doi. org/10.1890/1051-0761(2002)012[1434:CLCOAP]2.0. CO;2 ([1434:CLCOAP]2.0.CO;2)

Badano EI, Pugnaire FI (2004) Invasion of Agave species (Agavaceae) in south-east Spain: invader demographic parameters and impacts on native species. Divers Distrib 10:493-500. https://doi.org/10.1111/j.1366-9516.2004. 00086.x
Barbera G, Carimi F, Inglese P (1991) The reflowering of prickly pear Opuntia ficus-indica (L.) Miller: influence of removal time and cladode load on yield and fruit ripening. Adv Hortic Sci 5:77-80

Bein E, Habte B, Jaber A et al (1996) Useful trees and shrubs in Eritrea. Nairobi, Kenya

Bekele T (1994) Phytosociology and ecology of a humid Afromontane forest on the Central Plateau of Ethiopia. J Veg Sci 5:87-98. https://doi.org/10.2307/3235642

Brutsch M, Zimmermann H (1995) Control and utilization of wild Opuntias. FAO Plant Prod Prot Paper 132:155-166

Chen GQ, Zhang C, Bin, Ma L et al (2013) Biotic homogenization caused by the invasion of Solidago canadensis in China. J Integr Agric 12:835-845. https://doi.org/10.1016/ S2095-3119(13)60302-0

Dar PA, Reshi ZA (2015) Do alien plant invasions cause biotic homogenization of terrestrial ecosystems in the Kashmir Valley, India? Trop Ecol 56:111-123

Davis MA, Grime JP, Thompson K (2000) Fluctuating resources in plant communities: a general theory of invasibility. J Ecol 88:528-534. https://doi.org/10.1046/j.1365-2745. 2000.00473.x

Di Castri F, Groves R, Kruger F et al (1989) Biological invasions: a global perspective. Wiley, New York

Di Castri F, Hansen A, Debussche M (1990) Biological invasions in Europe and the Mediterranean Basin. Kluwer Academic Publishers, New York

Dufrêne M, Legendre P (1997) Species assemblages and indicator species: the need for a flexible asymmetrical approach. Ecol Monogr 67:345-366

Edwards S, Mesfin T, Hedberg I (1995) Flora of Ethiopia and Eritrea, Canellaceae to Euphorbiaceae. Addis Abeba, Ethiopia, Uppsala, Sweden

Edwards S, Sebsebe D, Hedberg I (1997) Flora of Ethiopia and Eritrea, Hydrocharitaceae to Arecaceae. Addis Abeba, Ethiopia, Uppsala, Sweden

Edwards S, Mesfin T, Sebsebe D, Hedberg I (2000) Flora of Ethiopia and Eritrea, Magnoliaceae to Flacourtiaceae. Addis Abeba, Ethiopia, Uppsala, Sweden

Ehrenfeld JG (2003) Effects of exotic plant invasions on soil nutrient cycling processes. Ecosystems 6:503-523. https:// doi.org/10.1007/s10021-002-0151-3

Erre P, Chessa I, Nieddu G, Jones PG (2009) Diversity and spatial distribution of Opuntia spp. in the Mediterranean Basin. J Arid Environ 73:1058-1066. https://doi.org/10. 1016/j.jaridenv.2009.05.010

Fridley JD, Stachowicz JJ, Naeem S et al (2007) The invasion paradox: reconciling pattern and process in species invasions. Ecology 88:3-17

Funk C, Nicholson SE, Landsfeld M et al (2015) The centennial trends greater horn of Africa precipitation dataset. Sci Data 2. https://doi.org/10.1038/sdata.2015.50

Gaertner M, Breeyen A, Den, Hui C, Richardson DM (2009) Impacts of alien plant invasions on species richness in mediterranean-type ecosystems: a meta-analysis. Prog Phys Geogr 33:319-338. https://doi.org/10.1177/ 0309133309341607

Gimeno I, Vilà M (2002) Recruitment of two Opuntia species invading abandoned olive groves. Acta Oecol 23:239-246. https://doi.org/10.1016/S1146-609X(02)01143-8 
Gurevitch J, Padilla DK (2004) Are invasive species a major cause of extinctions? Trends Ecol Evol 19:470-474. https://doi.org/10.1016/j.tree.2004.07.005

Hamilton AC (1976) The significance of patterns of distribution shown by forest plants and animals in tropical Africa for the reconstruction of Upper Pleistocene palaeoenvironments: a review. Palaeoecol Afr 9:63-96

Hedberg I, Edwards S (1989) Flora of Ethiopia, Pittosporaceae to Araliaceae. Addis Abeba, Ethiopia, Uppsala, Sweden

Hedberg I, Edwards S, Sileshi N (2003) Flora of Ethiopia and Eritrea, Apiaceae to Dipsacaceae. Addis Abeba, Ethiopia, Uppsala, Sweden

Hedberg I, Ensermu K, Edwards S et al (2006) Flora of Ethiopia and Eritrea, Gentianaceae to Cyclocheilaceae. Addis Abeba, Ethiopia, Uppsala, Sweden

Hejda M, Pyšek P (2006) What is the impact of Impatiens glandulifera on species diversity of invaded riparian vegetation? Biol Conserv 132:143-152. https://doi.org/10. 1016/j.biocon.2006.03.025

Hejda M, Pyšek P, Jarošík V (2009) Impact of invasive plants on the species richness, diversity and composition of invaded communities. J Ecol 97:393-403. https://doi.org/10.1111/j. 1365-2745.2009.01480.x

Hulme PE, Bremner ET (2006) Assessing the impact of Impatiens glandulifera on riparian habitats: partitioning diversity components following species removal. J Appl Ecol 43:43-50. https://doi.org/10.1111/j.1365-2664.2005. 01102.x

Johnson WR (1982) The fight against cacti pests in Queensland. Queensl Agric J 108:215-221

Jones CG, Lawton JH, Shachak M (1994) Organisms as ecosystem engineers. Oikos 69:373. https://doi.org/10. 2307/3545850

Juma BF, Midiwo JO, Yenesew A et al (2006) Three ent-trachylobane diterpenes from the leaf exudates of Psiadia punctulata. Phytochemistry 67:1322-1325. https://doi.org/ 10.1016/j.phytochem.2006.04.007

Juma BF, Yenesew A, Midiwo JO, Waterman PG (2001) Flavones and phenylpropenoids in the surface exudate of Psiadia punctulata. Phytochemistry 57:571-574. https:// doi.org/10.1016/S0031-9422(01)00147-9

Jurasinski G, Kreyling J (2007) Upward shift of alpine plants increases floristic similarity of mountain summits. J Veg Sci 18:711-718. https://doi.org/10.1111/j.1654-1103. 2007.tb02585.x

Kruskal JB (1964) Multidimensional scaling by optimizing goodness of fit to a nonmetric hypothesis. Psychometrika 29:1-27. https://doi.org/10.5137/1019-5149. JTN.14036 15.1

Kuznetsova A, Brockhoff PB, Christensen RHB (2017) lmerTest package: tests in linear mixed effects models. J Stat Softw. https://doi.org/10.18637/jss.v082.i13

Levine JM, D'Antonio CM (1999) Elton revisited: a review of evidence linking diversity and invasibility. Oikos 87:15. https://doi.org/10.2307/3546992

Liao C, Peng R, Zhou X et al (2008) Altered ecosystem carbon and nitrogen cycles by plant invasion: a meta-analysis. New Phytol 177:706-714. https://doi.org/10.1111/j.14698137.2007.02290.x

Lososová Z, Chytrý M, Danihelka J et al (2016) Biotic homogenization of urban floras by alien species: the role of species turnover and richness differences. J Veg Sci 27:452-459. https://doi.org/10.1111/jvs. 12381

Maskell LC, Firbank LG, Thompson K et al (2006) Interactions between non-native plant species and the floristic composition of common habitats. J Ecol 94:1052-1060. https:// doi.org/10.1111/j.1365-2745.2006.01172.x

McKinney ML (2005) Species introduced from nearby sources have a more homogenizing effect than species from distant sources: evidence from plants and fishes in the USA. Divers Distrib 11:367-374. https://doi.org/10.1111/j.13669516.2005.00181.x

Mesfin T (2004) Flora of Ethiopia and Eritrea, Asteraceae (Compositae). Addis Abeba, Ethiopia, Uppsala, Sweden

Midiwo JO, Yenesew A, Juma BF et al (2003) Bioactive compounds from some Kenyan ethnomedicinal plants: Myrsinaceae, Polygonaceae and Psiadia punctulata. Phytochem Rev 1:311-323

Morri C, Montefalcone M, Gatti G et al (2019) An Alien Invader is the cause of homogenization in the recipient ecosystem: a simulation-like approach. Diversity 11:1-15. https://doi. org/10.3390/d11090146

Müllerová J, Pyšek P, Jarošík V, Pergl J (2005) Aerial photographs as a tool for assessing the regional dynamics of the invasive plant species Heracleum mantegazzianum. J Appl Ecol 42:1042-1053. https://doi.org/10.1111/j.1365-2664. 2005.01092.x

NEMP-E (1995) Government of Eritrea: The National Environmental Management Plan for Eritrea. Asmara, Eritrea

Nieddu G, Chessa I (1997) Distribution of phenotypic characters within a seedling population from Opuntia ficus-indica (cv "Gialla"). Acta Hortic 438:37-43

Nobel PS (1994) Remarkable Agaves and Cacti. Oxford University Press, New York

Novoa A, Le Roux JJ, Robertson MP et al (2015) Introduced and invasive cactus species: a global review. AoB Plants 7:1-14. https://doi.org/10.1093/aobpla/plu078

Obiri JF (2011) Invasive plant species and their disaster-effects in dry tropical forests and rangelands of Kenya and Tanzania. Jàmbá J Disaster Risk Stud 3:417-428. https://doi. org/10.4102/jamba.v3i2.39

Oduor AMO, Long H, Fandohan AB et al (2018) An invasive plant provides refuge to native plant species in an intensely grazed ecosystem. Biol Invasions 20:2745-2751. https:// doi.org/10.1007/s10530-018-1757-5

Ogbazghi W, Stillhardt B (2011) Sustainable land management - a textbook with a focus on Eritrea. Geographica Bernensia and Hamelmalo Agricultural College, Bern

Oksanen J, Blanchet FG, Friendly M et al (2019) Vegan: community ecology package. Version 2.5-6. https://CRAN.Rproject.org/package $=$ vegan

Olden JD, Rooney TP (2006) On defining and quantifying biotic homogenization. Glob Ecol Biogeogr 15:113-120. https:// doi.org/10.1111/j.1466-822X.2006.00214.x

Pauchard A, Shea K (2006) Integrating the study of non-native plant invasions across spatial scales. Biol Invasions 8:399-413. https://doi.org/10.1007/s10530-005-6419-8

Pejchar L, Mooney HA (2009) Invasive species, ecosystem services and human well-being. Trends Ecol Evol 24:497-504. https://doi.org/10.1016/j.tree.2009.03.016

Pimentel D, McNair S, Janecka J et al (2001) Economic and environmental threats of alien plant, animal, and microbe 
invasions. Agric Ecosyst Environ 84:1-20. https://doi.org/ 10.1016/S0167-8809(00)00178-X

Pino J, Font X, de Cáceres M, Molowny-Horas R (2009) Floristic homogenization by native ruderal and alien plants in north-east Spain: the effect of environmental differences on a regional scale. Glob Ecol Biogeogr 18:563-574. https://doi.org/10.1111/j.1466-8238.2009.00458.x

Powell KI, Chase JM, Knight TM (2011) A synthesis of plant invasion effects on biodiversity across spatial scales. Am J Bot 98:539-548. https://doi.org/10.3732/ajb.1000402

Price EPF, Spyreas G, Matthews JW (2018) Biotic homogenization of regional wetland plant communities within short time-scales in the presence of an aggressive invader. J Ecol 106:1180-1190. https://doi.org/10.1111/1365-2745. 12883

Pyšek P, Pyšek A (1995) Invasion by Heracleum mantegazzianum in different habitats in the Czech Republic. J Veg Sci 6:711-718. https://doi.org/10.2307/3236442

Qian H, Ricklefs RE (2006) The role of exotic species in homogenizing the north American flora. Ecol Lett 9:1293-1298. https://doi.org/10.1111/j.1461-0248.2006. 00982.x

R Development Core Team (2019) A language and environment for statistical computing. R Foundation for Statistical Computing, Vienna

Richardson DM, Pyšek P (2006) Plant invasions: Merging the concepts of species invasiveness and community invasibility. Prog Phys Geogr 30:409-431. https://doi.org/10. 1191/0309133306pp490pr

Roberts WD (2019) Package ' labdsv'. Ordination and multivariate analysis for ecology. Version 2.0-1. https://CRAN. R-project.org/package=labdsv

Ruprecht E (2005) Secondary succession in old-fields in the Transylvanian Lowland (Romania). Preslia 77:145-157

Sax DF, Gaines SD, Brown JH (2002) Species invasions exceed extinctions on islands worldwide: a comparative study of plants and birds. Am Nat 160:766-783. https://doi.org/10. $1086 / 343877$

Serdeczny O, Adams S, Baarsch F et al (2017) Climate change impacts in Sub-Saharan Africa: from physical changes to their social repercussions. Reg Environ Chang 17:1585-1600. https://doi.org/10.1007/s10113-015-09102

Smart SM, Thompson K, Marrs RH et al (2006) Biotic homogenization and changes in species diversity across human-modified ecosystems. Proc R Soc B Biol Sci 273:2659-2665. https://doi.org/10.1098/rspb.2006.3630

Sol D, Maspons J, Vall-llosera M et al (2012) Unraveling the life history of successful invaders. Science 337:580-583. https://doi.org/10.1126/science.1221523

Staples GW (2001) The understorey of human dimensions in biological invasions. In: McNeely JA (ed) The great reshuffling: human dimensions of Alien invasive species. IUCN, Gland, pp 171-179
Stohlgren T, Rejmànek M (2014) No universal scale-dependent impacts of invasive species on native plant species richness. Biol Lett 10:2013093. https://doi.org/10.1098/rsbl. 2013.0939

Stohlgren TJ, Barnett DT, Jarnevich CS et al (2008) The myth of plant species saturation. Ecol Lett 11:313-322. https://doi. org/10.1111/j.1461-0248.2008.01153.x

Tura TT, Soromessa T, Leta S, Argaw M (2017) Plant community composition and structure of Asabot dry Afromontane forest, West Harare Zone, Ethiopia. J Biodivers Endanger Species 5:202. https://doi.org/10.4172/ 2332-2543.1000202

Van Kleunen M, Dawson W, Schlaepfer D et al (2010) Are invaders different? A conceptual framework of comparative approaches for assessing determinants of invasiveness. Ecol Lett 13:947-958. https://doi.org/10.1111/j.14610248.2010.01503.x

van Sittert L (2002) Our irrepressible fellow-colonist ': the biological invasion of prickly pear (Opuntia ficus-indica) in the Eastern Cape\&nbsp;c. 1890-c. 1910. J Hist Geogr 3:397-419. https://doi.org/10.1006/jhge.2001.0457

Vilà M, Tessier M, Suehs CM et al (2006) Local and regional assessments of the impacts of plant invaders on vegetation structure and soil properties of Mediterranean islands. J Biogeogr 33:853-861. https://doi.org/10.1111/j.13652699.2005.01430.x

Vilà M, Espinar JL, Hejda M et al (2011) Ecological impacts of invasive alien plants: a meta-analysis of their effects on species, communities and ecosystems. Ecol Lett 14:702-708. https://doi.org/10.1111/j.1461-0248.2011. 01628.x

White F (1983) The Vegetation of Africa. A descriptive memoir to accompany the UNESCO/AETFAT/UNSO vegetation map of Africa. UNESCO, Paris

Wilcove DS, Rothstein D, Dubow J et al (1998) Quantifying threats to imperiled species in the United States. Bioscience 48:607-615. https://doi.org/10.2307/1313420

Williamson M (1996) Biological invasions. Chapman and Hall, London

Wilson JRU, Richardson DM, Rouget M et al (2007) Residence time and potential range: crucial considerations in modelling plant invasions. Divers Distrib 13:11-22. https://doi. org/10.1111/j.1366-9516.2006.00302.x

Zimmermann H, Moran V (1991) Biological control of prickly pear, Opuntia ficus-indica (Cactaceae), in South Africa. Agric Ecosyst Environ 37:29-35

Zimmermann H, Moran C, Hoffmann J (2009) Invasive cactus species (Cactaceae). In: Muniappan R, Reddy GVP, Raman A (eds) Biological control of tropical weeds using Arthropods. Cambridge, U.K

Publisher's Note Springer Nature remains neutral with regard to jurisdictional claims in published maps and institutional affiliations. 